\title{
Assessment of the perception of fire risk through abandonment training in a rural school unit at a fundamental level
}

\author{
Camylla Kerly Pereira Mariano ${ }^{l}{ }^{*}$, Luciana Sanches $^{1}$, Vanusa de Souza Pacheco Hoki \\ ${ }^{1,2}$, Karen Mamoré de Matos ${ }^{1}$, Gersina N. da R. Carmo Junior ${ }^{1}$
}

\author{
${ }^{1}$ Universidade Federal de Mato Grosso (UFMT), Cuiabá, Mato Grosso, Brazil \\ ${ }^{2}$ Universidade de Cuiabá (UNIC), Cuiabá, Mato Grosso, Brazil \\ * E-mail for contact: camylla_kerly @ hotmail .com lsanches@hotmail.com, vanusahoki@gmail.com, \\ karenmamorematos@gmail.com,gersina@hotmail.com
}

\begin{abstract}
The District of Novo Mato Grosso is a rural community with approximately 800 inhabitants, located in the municipality of Nova Ubiratã / distant MT $570 \mathrm{~km}$ from Cuiabá, capital of Mato Grosso, Brazil. Due to regional economic activity the community is admittedly an environment susceptible to the occurrence of fires. The Getúlio Vargas Municipal Rural School, composed of 80 elementary students and 8 teachers, located in this district, was the object of study, due to the fact that the academic community will be a multiplier in actions to prevent local fires. As a result, this study carried out by the Forest and Burned Fire Control Program, which is part of the Environmental Management of BR-242 / MT, in its educational aspect, aimed at training the school community through awareness and awareness of fire prevention, and later the Area Abandonment Training. As a methodological strategy, first, an emergency map and escape route according to NBR 9077/2001 were elaborated through an exploratory analysis of the building, fire safety preventive and architectural plans; secondly, the perception and behavior of teachers and students in relation to the risk of occurrence of fire in the school were evaluated through the application of pre and post training questionnaires; and third, there was training with fire simulation for area abandonment. Considering the main results, it was concluded that: there was an improvement in the perception of teachers and students regarding the risk of fire in the school; and with the simulation of fire and the abandonment of the area, the school community involved proceeded in a correct way to abandon the established area, avoiding panic in an oriented and safe manner as they were directed, demonstrating that it is possible to abandon the school in less than 1 minute. As future training in the school environment, it is recommended to include the theme of fire prevention in the Pedagogical Project; as well as the elaboration of the Emergency Plan, with regular training and simulations in addition to the adequacy of the school building regarding the requirements of the Fire Department, mainly in relation to basic safety requirements.
\end{abstract}

Keywords: rural community, Novo Mato Grosso district, Nova Ubiratã/ MT municipality, escape route, fire simulation. 